\section{Regime-Dependent Recession Forecasts and the 2001 Recession}

\author{
Michael J. Dueker
}

D usiness recessions, as a major source of nondiversifiable risk, impose high costs on society. Since firms cannot obtain "recession insurance," they try to foresee recessions and reduce their exposure ahead of time. Consequently, forecasting business cycle turning points has remained an important endeavor. Of course, the difficulty is deriving reliable methods to forecast business cycle turning points. Previous studies found that accurate recession forecasts remain elusive (Filardo, 1999; Del Negro, 2001; Chin, Geweke, and Miller, 2000). Forecasts of economic output are not a good substitute for forecasts of business cycle turning points because less than 20 percent of all months pertain to recessions. Hence, empirical models of output growth focus largely on explaining variation in output growth during economic expansions, since this variation accounts for the lion's share of the sample variance.

Throughout the 1990s, recession forecasting models relied exclusively on the 1990-91 recession for out-of-sample confirmation (Estrella and Mishkin, 1998; Birchenhall et al., 1999; Friedman and Kuttner, 1998). Out-of-sample confirmation is particularly important for recession forecasting because reces sions are infrequent, making it tempting to overfit specific episodes in sample. In general, recession forecasting models failed to predict the 1990-91 recession out of sample. The occurrence of the 2001 recession raises the question: Was the 1990-91 recession uniquely difficult to predict or is recession forecasting a failed enterprise? If recession forecasting models were to repeat in 2001 their dismal performance from the 1990-91 recession, then doubts about such models would mount with justification. In this article, I examine the out-of-sample forecasts from recession forecasting models with three levels of sophistication. All three models concur with the previous finding that the 1990-91 recession was

Michael J. Dueker is a research officer at the Federal Reserve Bank of St. Louis. Mrinalini Lhila and John Zhu provided research assistance.

(C) 2002, The Federal Reserve Bank of St. Louis. hard to predict. The simplest of the three models largely misses the 2001 recession, but two regimeswitching models come quite close to predicting the onset date of the recession six months ahead of time. One innovation to recession forecasting introduced here is to allow the critical probability level for a recession to be predicted to depend on the current state of a Markov switching processhence, regime-dependent recession forecasts.

In this way, the forecasts presented here respond to the criticism that economists equivocate too much when it comes to their recession forecasts. When recession forecasts are expressed as probability statements, it is tempting to claim ex post that the ex ante probability of recession from the forecasting model was "close enough" to either one or zero to be considered a correct forecast. For example, if the model suggested that a recession would occur with a probability of 35 percent, then after the fact the model builder could try to justify either outcome: If a recession ensued, the model builder could cite the jump in probability from zero to 35 percent as evidence that a large shift toward recession was detected; if no recession ensued, the model builder could say that the 35 percent probability was far from 100 percent and did not indicate recession. To avoid such ambiguity, economists are often asked to make specific calls as to whether the economy will or will not be in recession six months from now. A yes/no recession signal comes from comparing the forecasted probability of recession with a critical value determined prior to the out-of-sample forecasting.

The dependent variable I use to separate business recessions from expansions is based on the business cycle turning points defined by the National Bureau of Economic Research (NBER). As in Birchenhall et al. (1999), I use the composite index of leading indicators (CLI) from the Conference Board as the explanatory variable in the probit forecasting models. The CLI receives much attention as a harbinger of future business cycle conditions. It has ten components: manufacturing hours, consumer expectations, stock prices, initial unemployment claims, building permits, the money supply, the spread between short- and long-term interest rates on government securities, vendor performance, manufacturing orders for consumer goods, and manufacturing orders for capital goods. Figure 1 shows the upward trend in the CLI and its three-month percentage changes. The decreased volatility in the three-month change since the early 1980 s is symptomatic of decreased volatility in the business cycle. 


\section{Figure 1}

\section{Index of Leading Indicators}

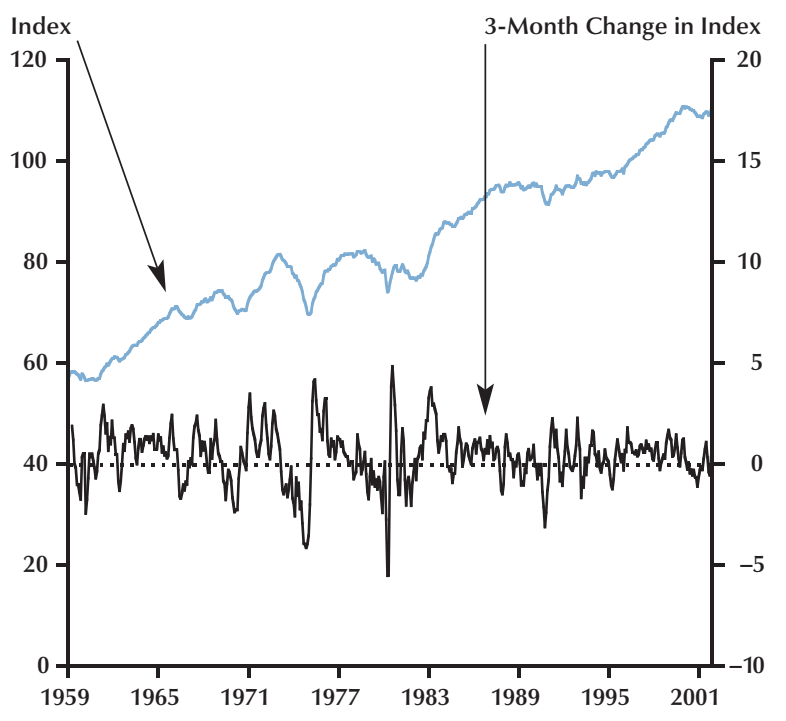

The 1990-91 and 2001 recessions can be used to evaluate the out-of-sample performance of the model and the leading indicators. I find that the 1990-91 recession is the anomaly in that the recession signal emanating from the leading indicators largely misses it. The 2001 recession, in contrast, was largely predictable from the leading indicators six months ahead.

The probit model takes the monthly movements in the leading indicators and translates them into precise probability statements regarding the likelihood of recession. When dealing with qualitative events such as recessions, however, it is often desirable to define a specific recession yes/no signal from the probit probabilities. That way, the forecasting method either correctly "calls" the recession or it does not. Birchenhall et al. (1999) use this approach to say that a recession is signaled if the logit probability of recession exceeds a critical value. If one chooses the critical value to maximize the in-sample fit, then out-of-sample confirmation of recession forecasting models becomes particulary important, given Robert Lucas's dictum: Beware of econometricians bearing free parameters. The critical value that defines a recession signal is an example of what Lucas calls a free parameter because-although it is not an inherent part of the econometric modelit combines with the model estimates to suggest that the model fits the data well. Out-of-sample confirmation helps ensure that the free parameters are not simply overfitting the in-sample data.

\section{THE SIMPLE PROBIT MODEL}

I study three probit forecasting methods. One is the simple probit model and the other two are based on a Markov switching probit from Dueker (1997). A probit model can be used to predict a qualitative variable such as a recession indicator, $R_{t}$, where

$R_{t}=1$ if the economy is in NBER recession in period $t$

$=0$ otherwise.

One way to think of a probit model is to assume that a normally distributed latent variable, $R^{*}$, lies behind the recession indicator:

$$
R_{t}^{*}=-c_{0}+-c_{1} X_{t-k}+u_{t},
$$

where $u$ is a normally distributed error team and $X$ is the leading indicator explanatory variable lagged $k$ periods - the forecasting horizon. A probability of recession is associated with each possible value of the latent variable, where the latent variable is assumed to be negative during expansions and positive during recessions. In this case, the forecasted probability of recession is

$$
\operatorname{Prob}\left(R_{t}=1\right)=1-\Phi\left(c_{0}+c_{1} X_{t-k}\right),
$$

where $\Phi($.$) is the cumulative standard normal density$ function.

The log-likelihood function for a simple probit model is

$$
\begin{aligned}
L & =\sum_{t} R_{t} \ln \operatorname{Prob}\left(R_{t}=1 \mid X_{t-k}\right) \\
& +\left(1-R_{t}\right) \ln \operatorname{Prob}\left(R_{t}=0 \mid X_{t-k}\right) .
\end{aligned}
$$

\section{COEFFICIENT VARIATION VIA MARKOV SWITCHING IN THE PROBIT MODEL}

The log-likelihood function in equation (3) highlights the assumption in the probit model that the recession outcomes conditional on available information are independently distributed from month to month. This assumption is questionable unless the econometric model allows for considerable serial correlation in the recession probabilities. As in Dueker (1997), one way to achieve this degree of serial correlation is to introduce serial correlation in the model's coefficients by making them subject to Markov switching.

The simplest interpretation of Markov switching coefficients in a probit model is that they capture time variation in the variance of the error term $u$ from equation (1). In the low-variance regime the variance would still be normalized to one, but in 
the high-variance regime the variance would be greater than one:

$$
\begin{aligned}
& \operatorname{Prob}\left(R_{t}=1 \mid \text { High Variance }\right) \\
& =1-\Phi\left(c_{0} / \sigma+c_{1} / \sigma X_{t-k}\right), \sigma>1 .
\end{aligned}
$$

Variance switching implies that the coefficients are restricted to change by the same percentage between regimes. I do not impose this condition because I do not want to restrict the signs of the coefficients, for example, to be the same in both regimes. Nevertheless, conditional heteroskedasticity helps motivate why the coefficients might be subject to regime switching, since volatility is one aspect of the economy that does vary across the business cycle. Because it is not the only aspect of the economy that varies across the business cycle, however, we keep the model more general by not restricting the regime switching to variance switching.

In a Markov switching model, the parameters change values according to an unobserved binary state variable, $S_{t}$, which follows a Markov process:

$$
\begin{aligned}
& S_{t} \text { equals } 0 \text { or } 1 \\
& \operatorname{Prob}\left(S_{t}=0 \mid S_{t-1}=0\right)=p \\
& \operatorname{Prob}\left(S_{t}=1 \mid S_{t-1}=1\right)=q .
\end{aligned}
$$

In this way, the coefficients take on either of two values and thereby change the magnitude of the shock needed to induce a recession:

$$
\begin{aligned}
R_{t} & =1 \quad \text { if } \quad u_{t}>c_{0}\left(S_{t}\right)+c_{1}\left(S_{t}\right)+c_{1}\left(S_{t}\right) X_{t-k} \\
& =0 \text { if } u_{t} \leq c_{0}\left(S_{t}\right)+c_{1}\left(S_{t}\right) X_{t-k} .
\end{aligned}
$$

The transition probabilities, $p$ and $q$, indicate the persistence of the states and determine the unconditional probability of the state $S_{t}=0$ to be $(1-q) /(2-p-q)$. Since the state is unobserved and must be inferred as a probability, allowance for two states means that the expected values of the coefficients can lie anywhere between the high and low values corresponding to the two states. In the estimation, Bayes' rule is used to obtain filtered probabilities of the states in order to sum over possible values of the unobserved states and evaluate the likelihood function, as in Hamilton (1990):

(6)

$$
\begin{aligned}
& \operatorname{Prob}\left(S_{t}=0 \mid R_{t}=0, X_{t-1}\right)= \\
& \frac{\operatorname{Prob}\left(S_{t}=0 \mid R_{t-1}, X_{t-2}\right) \operatorname{Prob}\left(R_{t}=0 \mid S_{t}=0, X_{t-1}\right)}{\sum_{s=0}^{1} \operatorname{Prob}\left(S_{t}=s \mid R_{t-1}, X_{t-2}\right) \operatorname{Prob}\left(R_{t}=0 \mid S_{t}=s, X_{t-1}\right)}
\end{aligned}
$$

$$
\begin{aligned}
& \operatorname{Prob}\left(S_{t}=0 \mid R_{t-1}, X_{t-2}\right) \\
& =p \operatorname{Prob}\left(S_{t-1}=0 \mid R_{t-1}, X_{t-2}\right) \\
& +(1-q) \operatorname{Prob}\left(S_{t-1}=1 \mid R_{t-1}, X_{t-2}\right) .
\end{aligned}
$$

The probability in equation (7) is called the oneperiod-ahead prior probability because it is not conditional on the recession outcome at time $t$. For a forecast horizon of several months, we need to use the transition probabilities to derive a $k$-period-ahead probability of the state variable:

(8)

$$
\begin{gathered}
\left(\begin{array}{l}
\operatorname{Prob}\left(S_{t}=0 \mid R_{t-k}, X_{t-k}\right) \\
\operatorname{Prob}\left(S_{t}=1 \mid R_{t-k}, X_{t-k}\right)
\end{array}\right)^{\prime}= \\
G^{k}\left(\begin{array}{l}
\operatorname{Prob}\left(S_{t-k}=0 \mid R_{t-k}, X_{t-k}\right) \\
\operatorname{Prob}\left(S_{t-k}=1 \mid R_{t-k}, X_{t-k}\right)
\end{array}\right)^{\prime},
\end{gathered}
$$

where $G$ is the transition matrix of the Markov state variable.

For forecasting $k$ periods ahead, one finds the best-fitting model by maximizing the corresponding likelihood function:

(9)

$$
\begin{aligned}
& \sum_{t=1}^{T} R_{t} \ln \left(\begin{array}{l}
\sum_{s=0}^{1} \operatorname{Prob}\left(S_{t}=s \mid R_{t-k}, X_{t-k}\right) \\
\operatorname{Prob}\left(R_{t}=1 \mid S_{t}=s, X_{t-k}\right)
\end{array}\right) \\
& +\left(1-R_{t}\right) \ln \left(\begin{array}{l}
\sum_{s=0}^{1} \operatorname{Prob}\left(S_{t}=s \mid R_{t-k}, X_{t-k}\right) \\
\operatorname{Prob}\left(R_{t}=0 \mid S_{t}=s, X_{t-k}\right)
\end{array}\right) .
\end{aligned}
$$

In this forecasting exercise, the forecaster is assumed to know whether the economy is currently in recession when forecasting whether the economy will be in recession six months from now. This assumption is somewhat problematic when forecasting from the early stages of a recession before the NBER has officially declared that the economy entered a recession. For example, when forecasting whether the economy would be in recession in October 2001, it was probably not clear that the economy was in recession in April 2001. The NBER did not announce that the recession had started in March 2001 until November 26, 2001. On the other hand, forecasts of the onsets of recessions are not likely to be clouded by this assumption. In forecasting whether the economy would be in recession in 


\section{Figure 2}

\section{Probability of Recession Conditional on Regime $S=0$}

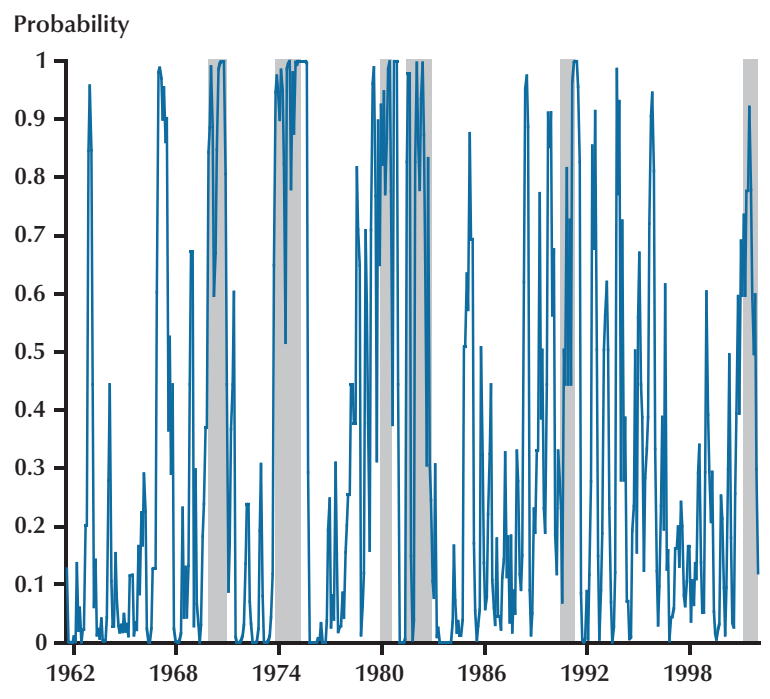

NOTE: Shaded bars indicate recessions.

\section{Table 1}

\section{Coefficients from the Markov Switching Probit}

\begin{tabular}{lc} 
Equation & Coefficient value \\
\hline$c_{0}(S=0)$ & $0.140(0.233)$ \\
$c_{1}(S=0)$ & $1.415(0.336)$ \\
$c_{0}(S=1)$ & $2.397(0.730)$ \\
$c_{1}(S=1)$ & $-0.062(0.351)$ \\
$p$ & $0.950(0.012)$ \\
$q$ & $0.984(0.010)$
\end{tabular}

NOTE: Standard errors are in parentheses.

March or April 2001, no one believed in September or October 2000 that the economy was already in recession. There was no confusion about the current state of the economy. Similarly, in January 1990 everyone knew that the economy was still in an expansion when forecasting whether a recession would start by July 1990 . For this reason, one might pay special attention to how the model predicts the onset dates of recessions.

\section{FORECAST RESULTS}

The Markov switching probit model was estimated with data from May 1960 to December 1989.

\section{Figure 3}

Six-Month-Ahead Probability of Regime $S=0$

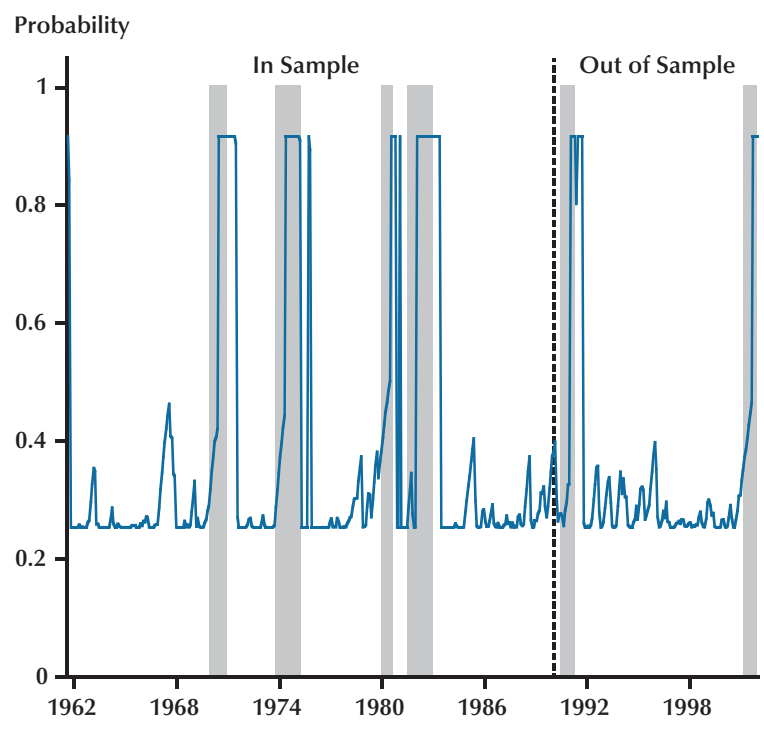

NOTE: Shaded bars indicate recessions.

The explanatory variable, $X$, is the three-month percentage change in the leading indicators index shown in Figure 1. The minimum value of the change in the leading indicators index is about -5 . If we plug this minimum value and the coefficient estimates from Table 1 into equation (5), we see that a recession is essentially never predicted in the state where $S=1$. Given the values of $c_{0}(S=1)$ and $c_{1}(S=1)$, a standard normal shock, $u$, greater than 2.7 would have to occur at the minimum value of the leading indicators for a recession to occur in that state. In contrast, recessions are often implied in the regime where $S=0$, as shown in Figure 2. (Note that in this and the following charts, the coefficient estimates are also applied to the out-of-sample data from January 1990 to December 2001.) The unconditional probability of the regime $S=0$, however, is only 0.25 and it is forecasted less often than regime $S=1$, as seen in Figure 3. Combining Figures 2 and 3, we see that six-month-ahead forecasts of a high probability of $S=0$ amount to a forecast of recession. Figure 4 combines the two explicitly by plotting the probability of recession after summing across the two states:

(10)

$$
\begin{aligned}
& \operatorname{Prob}\left(R_{t}=1 \mid X_{t-k}\right) \\
& =\sum_{s=0}^{1} \operatorname{Prob}\left(S_{t}=s \mid R_{t-k}, X_{t-k}\right) \operatorname{Prob}\left(R_{t}=1 \mid S_{t}=s, X_{t-k}\right) .
\end{aligned}
$$


A standard approach - which I call model 1to deriving explicit recession signals from the forecasted probability of recession, Prob $\left(R_{t}=1 \mid X_{t-k}\right)$, is to choose a critical value, $m$, such that a recession is signaled if

$$
\operatorname{Prob}\left(R_{t}=1 \mid X_{t-k}\right)-m>0 .
$$

A key innovation in this paper is to recognize that one can derive an alternative recession signalcalled model 2-from regime-specific critical values, $m_{0}$ and $m_{1}$, such that a recession is signaled if

$$
\begin{gathered}
\operatorname{Prob}\left(S_{t}=0 \mid R_{t-k}, X_{t-k}\right) \\
\left(\operatorname{Prob}\left(R_{t}=1 \mid S_{t}=0, X_{t-k}\right)-m_{0}\right) \\
+\operatorname{Prob}\left(S_{t}=1 \mid R_{t-k}, X_{t-k}\right) \\
\quad\left(\operatorname{Prob}\left(R_{t}=1 \mid S_{t}=1, X_{t-k}\right)-m_{1}\right)>0 .
\end{gathered}
$$

Alternatively, one can rewrite this recession signal as

$$
\begin{aligned}
\operatorname{Prob}\left(R_{t}=1 \mid X_{t-k}\right) & >\operatorname{Prob}\left(S_{t}=0 \mid R_{t-k}, X_{t-k}\right) m_{0} \\
& +\operatorname{Prob}\left(S_{t}=1 \mid R_{t-k}, X_{t-k}\right) m_{1}
\end{aligned}
$$

Either way, two critical values are used, where the weight given to each depends on the regime probabilities. As shown in Figure 2, the probability of recession is relatively high on average in the regime where $S=0$, with an average probability of 0.34 . In contrast, the average probability of recession in the regime where $S=1$ is not much above zero. Given the difference between the average probabilities of recession in the two regimes, it seems desirable to have separate critical probability levels for each regime, as in equation (12).

I chose critical probability levels based on the in-sample period through 1989 and examined how well they work in the out-of-sample period. The criterion I used was the greatest number of correct signals, where one point was given to a correct signal during a recession and half a point to a correct signal during an expansion. This point scheme puts greater emphasis on not missing recessions versus supplying false recession signals during expansions. The impetus for this asymmetry in the point scheme is the belief that most firms would be more willing to pay for recession insurance than for a contract that would indemnify them in the case where the economy performed above expectations when a recession was forecast.

\section{Figure 4}

\section{Probability of Recession from} Six-Month-Ahead Forecasts

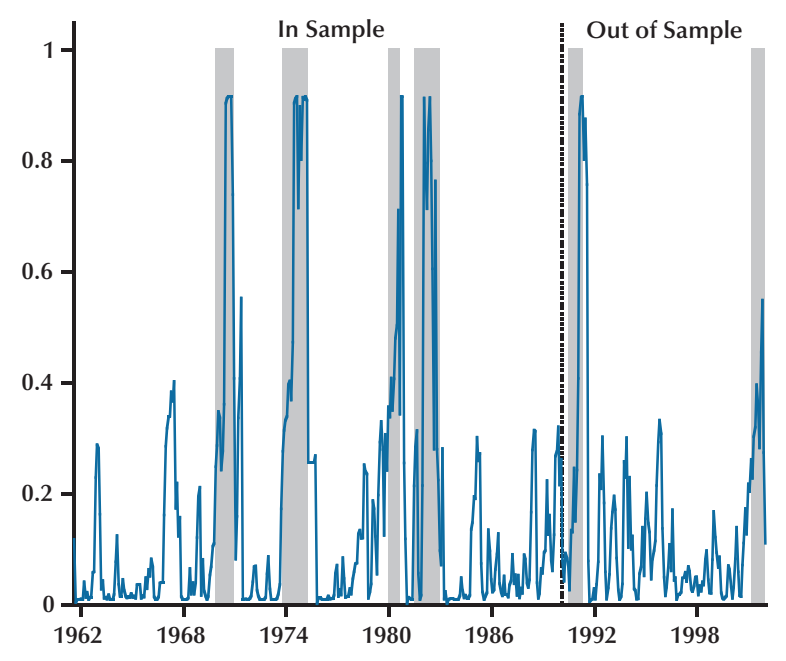

NOTE: Shaded bars indicate recessions.

For the in-sample period through 1989, I found that values of $m=0.28$ (for model 1) and $m_{0}=0.43$ and $m_{1}=0.135$ (for model 2 ) gave the greatest number of correct signals. It makes sense that the optimal value of $m$ would lie between optimal $m_{0}$ and $m_{1}$, since it is trying to fill both roles. The critical probability level $m_{0}$ lies above the average probability of recession conditional on $S=0$ (0.34), so that one predicts a recession less than half of the time that $S=0$.

Figure 5 shows the fit of the recession-signaling model, where the signal is based on model 2 with the two regime-dependent critical values. With forecasts from model 2 , recessions are generally not missed and the only notable false signal occurred in the 1966 slowdown. Figure 6, in turn, shows the fit of model 1 -the signaling procedure that uses only one critical value, as in equation (11). Here, some of the recessions are projected to start earlier and end later than they did and there are many more false recession signals during expansions.

Similarly, Figure 7 shows the fit of the signal from the simple probit model from equation (2). The optimal critical value, $m$, for the 1960-89 period is 0.24 . This approach, model 3 , generated even more and longer-lasting false recession signals than the Markov switching model with one critical value (model 1). Based on these results, we do not look 


\section{Figure 5}

Fit of Recession-Signaling Model

(Model 2: Two Critical Values)

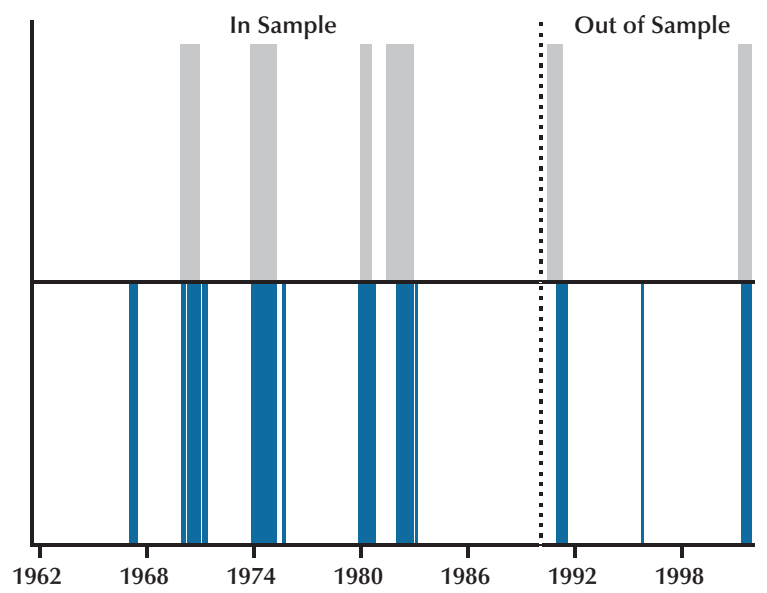

NOTE: Actual recessions (top) and six-month-ahead recession signals (bottom).

\section{Figure 6}

\section{Fit of Recession-Signaling Model}

(Model 1: One Critical Value)

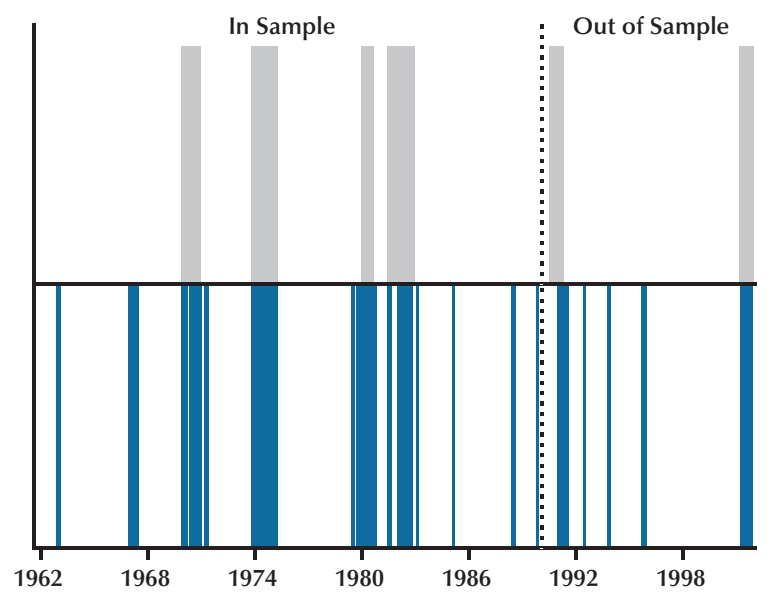

NOTE: Actual recessions (top) and six-month-ahead recession signals (bottom).

further at the predictions from the simple probit model.

In comparing the two signals from the Markov switching models, a closer look at the two out-ofsample recessions will help determine whether the

\section{Figure 7}

Fit of Recession Signal from Simple Probit Model (Model 3)

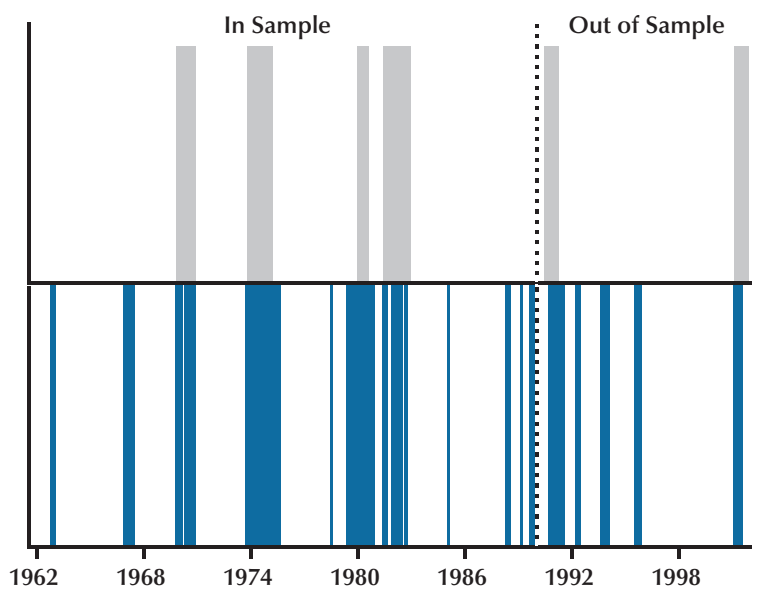

NOTE: Actual recessions (top) and six-month-ahead recession signals (bottom).

\section{Figure 8}

1990-91 Recession and Signal

(Signals from Models 1 and 2 Coincide: One or Two Critical Values)

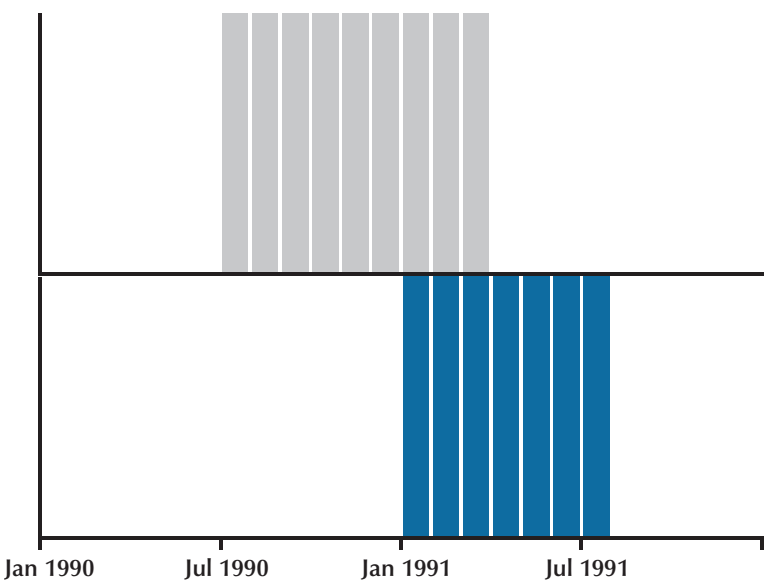

NOTE: Actual recession (top) and six-month-ahead recession signal (bottom).

use of two critical values in model 2 as free parameters to fit the in-sample data resulted in overfitting. Figure 8 zooms in on the 1990 recession and shows that the recession signals from models 1 and 2 are identical and they both miss the 1990 recession in 


\section{Figure 9}

\section{Recession and Signal}

(Model 1: One Critical Value)

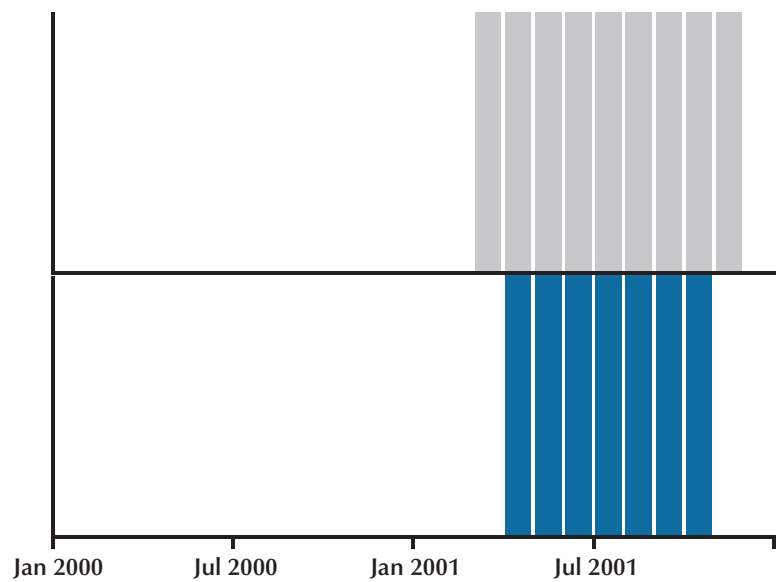

NOTE: Actual recession (top) and six-month-ahead recession signal (bottom).

the sense that the six-month-ahead signal does not kick in until at least six months too late. This result confirms previous findings that the 1990 recession was difficult to predict out of sample.

Fortunately, the performance of both signal approaches is better in the 2001 recession. Figure 9 shows that the signal from model 1 with one critical value predicted a recession onset in April 2001 using information through October 2000. Thus, this signal did not miss the actual onset date of March 2001 by much. The approach with two critical valuesmodel 2-does slightly worse during the 2001 recession. Figure 10 shows that this signal needed data through November 2000 to predict a recession onset date of May 2001. In addition, it incorrectly projected August 2001 as an expansion month. Nevertheless, one has to keep Figures 5 and 6 in mind before concluding that the signal derived from one critical value is better out of sample than the signal derived from two critical values. Model 2 gave fewer false recession signals than model 1 during the long economic expansion of the 1990s, as seen by comparing Figures 5 and 6.

Looking out from the December 2001 data, both signaling approaches based on the Markov switching model - with either one or two critical values - predict that the recession would have ended by January 2002 . Later, the NBER will officially date the end of the recession and then the accuracy of

\section{Figure 10}

2001 Recession and Signal

(Model 2: Two Critical Values)

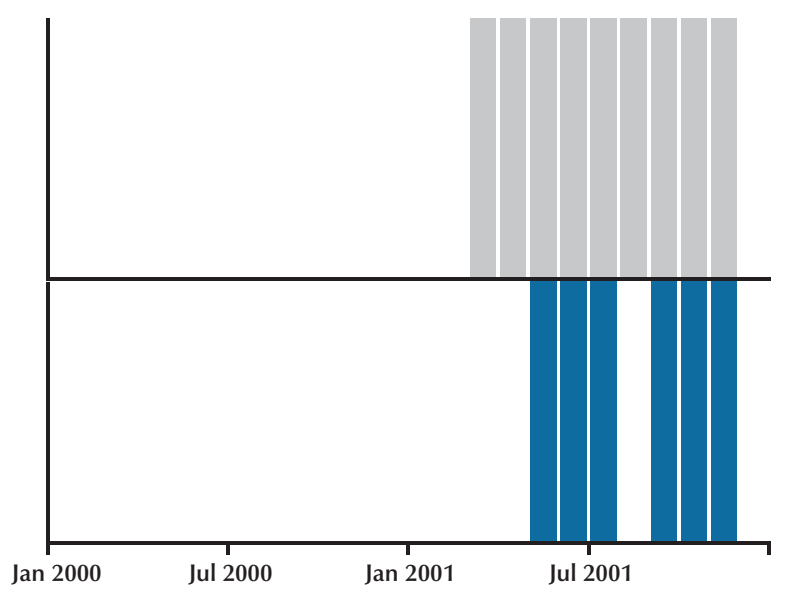

NOTE: Actual recession (top) and six-month-ahead recession signal (bottom).

the model's trough prediction will be known.

\section{SUMMARY AND CONCLUSIONS}

This article looks at forecasting the 1990 and 2001 recessions out of sample and shows that 1990 appears to be an anamoly in terms of being difficult to predict. Thus, one should not conclude based on the 1990 recession that recession forecasting is a failed enterprise. This article also responds to the exhortation economists receive to provide unequivocal predications about whether or not the economy will be in recession in six months. To translate from a probability of recession to a yes/no recession signal, one compares the probability with a critical value. One innovation in recession signaling that I pursue here is to have regime-specific critical values when the recession probability comes from a regimeswitching model. This method of deriving a recession signal reduces the number of false recession signals outside of recession, without impairing the ability to signal the recessions that occur.

\section{REFERENCES}

Birchenhall, Chris R.; Jessen, Hans; Osborn, Denise R. and Simpson, Paul. "Predicting U.S. Business-Cycle Regimes." Journal of Business and Economic Statistics, July 1999, 17(3), pp. 313-23.

Chin, Dan M.; Geweke, John F. and Miller, Preston J. "Predicting 
Turning Points." Federal Reserve Bank of Minneapolis Staff Report No. 267, June 2000.

Del Negro, Marco. “Turn, Turn, Turn: Predicting Turning Points in Economic Activity." Federal Reserve Bank of Atlanta Economic Review, Second Quarter 2001, 86(2), pp. 1-12.

Dueker, Michael. "Strengthening the Case for the Yield Curve as a Predictor of U.S. Recessions.” Federal Reserve Bank of St. Louis Review, March/April 1997, 79(2), pp. 41-51.

Estrella, Arturo and Mishkin, Frederic S. "Predicting U.S. Recessions: Financial Variables as Leading Indicators." Review of Economics and Statistics, February 1998, 80(1), pp. 45-61.

Filardo, Andrew J. "How Reliable Are Recession Prediction Models?" Federal Reserve Bank of Kansas City Economic Review, Second Quarter 1999, 84(2), pp. 35-55.

Friedman, Benjamin M. and Kuttner, Kenneth N. "Indicator Properties of the Paper-Bill Spread: Lessons from Recent Experience." Review of Economics and Statistics, February 1998, 80(1), pp. 34-44.

Hamilton, James D. "Analysis of Time Series Subject to Changes in Regime." Journal of Econometrics, July/August 1990, 45(1/2), pp. 39-70. 